\title{
Predictors of subclinical shoulder joint affection in patients with rheumatoid arthritis by ultrasonography
}

\author{
Samah M. Alian ${ }^{1 *}$ DD, Elsayed A. Elsiad ${ }^{1}$, Alzahraa E. Elsayed ${ }^{2}$ and Mohamed A. Hammad
}

\begin{abstract}
Background: To assess subclinical involvement of shoulder joints in patients with rheumatoid arthritis (RA) by using musculoskeletal ultrasound (MSUS) and detect their predictors.

Results: We found $75 \%$ of the patients have subclinical ultrasound changes in their shoulder joints where $65 \%$ of the patient's shoulders are affected. About $57.5 \%$ of the shoulder joints showed peri-articular structural changes by ultrasound, while the articular changes were $36.9 \%$ with the most frequent one being supraspinatus tendinopathy (43.12\%) followed by subacromial-subdeltoid bursitis [total (31.87\%), effusion (16.87\%), and synovial hypertrophy (15\%)], supraspinatus tendon partial tear (30.62\%), and long head of biceps tenosynovitis (effusion only) (28.75\%), while the least frequencies were glenohumeral joint erosion (11.25\%) and synovitis (12.5\%). Older age and longer disease duration were significant predictors for the peri-articular changes with $p$ value $<0.5$, while high disease activity, seropositive rheumatoid factor, and long disease duration were significant predictors for the articular changes with $p$ value $<0.5$.

Conclusion: Although shoulders were clinically silent in RA patients, we found a high percentage of subclinical abnormalities detected by MSUS, which were more predominant in the peri-articular structures. MSUS is a simple and non-invasive technique that can be used to detect RA shoulder subclinical affection.
\end{abstract}

Keywords: Subclinical arthritis, MSUS, Shoulder, Rheumatoid arthritis

\section{Background}

Rheumatoid arthritis (RA) is a progressive inflammatory autoimmune disease with articular and systemic effects. The exact cause is unknown, but genetic and environmental factors are contributory. Although some patients have mild self-limited disease, many experience joint destruction, severe physical disability, and multiple comorbidities [1]. RA involves the shoulder and is usually manifested by tenderness, pain, and limitation of movement, but few percent of RA patients have clinically detectable tenderness and swelling [2]. Considering the importance of early treatment in RA patients before the

\footnotetext{
* Correspondence: dr_r18@yahoo.com

${ }^{1}$ Rheumatology and Rehabilitation Department, Faculty of Medicine, Zagazig University, Zagazig, Egypt

Full list of author information is available at the end of the article
}

damage occurrence, musculoskeletal ultrasonography (MSUS) has an important role in detecting abnormalities in rheumatoid shoulder to achieve low disease status and eventually remission. It is proven to be a valid tool in the assessment of inflammatory arthritis, including RA and more sensitive than clinical examination in such joints [3].

\section{Methods \\ Patients}

This study was carried out in Rheumatology and Rehabilitation Departments, Faculty of Medicine, Zagazig University Hospitals, on 80 patients (58 females and 22 males) with RA diagnosed according to 2010 American College of Rheumatology/European League Against Rheumatism (ACR/EULAR) classification criteria for RA [4].

\section{Springer Open}

(อ) The Author(s). 2020 Open Access This article is licensed under a Creative Commons Attribution 4.0 International License, which permits use, sharing, adaptation, distribution and reproduction in any medium or format, as long as you give appropriate credit to the original author(s) and the source, provide a link to the Creative Commons licence, and indicate if changes were made. The images or other third party material in this article are included in the article's Creative Commons licence, unless indicated otherwise in a credit line to the material. If material is not included in the article's Creative Commons licence and your intended use is not permitted by statutory regulation or exceeds the permitted use, you will need to obtain permission directly from the copyright holder. To view a copy of this licence, visit http://creativecommons.org/licenses/by/4.0/. 
Written informed consent was obtained from patients for their study participation. The study was approved by the local ethical committee of Zagazig University Hospitals.

\section{Exclusion criteria}

Patients with other inflammatory autoimmune diseases, clinically evident shoulder affection (by history and clinical shoulder examination), and history of shoulder surgery, trauma, infection, fracture, or malignancy were excluded from the study

\section{Type of study: observational cross-sectional study Data collection}

All patients were subjected to full history taking, clinical examination, and especially full shoulder joint examination with special tests for shoulder joint and laboratory investigations including complete blood count, erythrocyte sedimentation rate (ESR) [5], C reactive protein (CRP), rheumatoid factor (RF), and anti-cyclic citrullinated peptide (anti-CCP) antibodies [6].. RA disease activity was evaluated by 28 -joint count disease activity score (DAS-28 score) [7].

\section{Shoulder examination}

Inspection for swelling or deformity, palpation for tenderness and warmth, range of motion both active and passive, and special tests for shoulder joint peri-articular structure affection such as Neer's test for impingement syndrome, Hawkin's test for supraspinatous tendinitis, drop arm test for rotator cuff tear, lift-off test for subscapularis tendon tear, empty can test for supraspinatous tendon tear, and Speed's and Yergason's tests for long head of biceps tenosynovitis were done.

\section{Ultrasonography}

MSUS was done to all patients at the musculoskeletal unit of the department by one rheumatologist trained in MSUS who was blind to the clinical and laboratory data of the patients. Ultrasound was done by both (gray scale and power Doppler) using high frequency superficial ultrasound probe by Hitachi Aloka F37 ultrasound device with a linear probe frequency (10-18) $\mathrm{MHz}$ transducer. MSUS (patient position and standard scans) are done according to the European League Against Rheumatism (EULAR) guidelines for MSUS examination [8]. The following anatomical areas were scanned in both shoulder joints (right and left): glenohumeral joint, acromioclavicular joint, biceps tendon, subacromial subdeltoid (SASD) bursa, and rotator cuff tendons (supraspinatus, subscapularis, infraspinatus, and teres minor). Structural pathology is defined according to the outcome measures in rheumatology clinical trials (OMERACT) definitions of pathology in MSUS [9], in which:
Synovial hypertrophy (synovitis) is defined as abnormal hypoechoic (relative to subdermal fat, but sometimes may be isoechoic or hyperechoic) intraarticular tissue that is nondisplaceable and poorly compressible and which may exhibit Doppler signal.

Synovial effusion is defined as abnormal hypoechoic or anechoic (relative to subdermal fat, but sometimes may be isoechoic or hyperechoic) intraarticular material that is displaceable and compressible, but does not exhibit Doppler signal.

Tenosynovitis is defined as hypoechoic or anechoic thickened tissue with or without fluid within the tendon sheath, which is seen in 2 perpendicular planes and which may exhibit Doppler signal.

Erosion is defined as an intraarticular discontinuity of the bone surface that is visible in 2 perpendicular planes.

Osteophyte is defined as linear bony outcropping adjacent to the joint.

Bursitis is defined as an increase of hypoechoic fluid and/or tissue depending on its nature within the bursa and may show Doppler signals

Tendinopathy is thickened/thinned and heterogenous, with loss of the normal fibrillar echopattern (architectural distortion)

Tendon tear is defined as hypoechoic area within the tendon at both planes at the articular/bursal surface or intrasubstance.

\section{Statistical analysis}

All data were collected, tabulated, and statistically analyzed using SPSS 20.0 for windows (SPSS Inc., Chicago, IL, USA). Quantitative data were expressed as the mean \pm SD and qualitative data were expressed as absolute frequencies (number) and relative frequencies (percentage). Student's $t$ test was used to compare between two groups of normally distributed variables. Mann-Whitney test was used to compare between two groups of nonparametric variables. Percent of categorical variables was compared using chi-square test or Fisher's exact test when appropriate. Multiple regression was used for detecting predicting factors for a dependant variable on several independent variables. All tests were two-sided. $p$ value $<0.05$ was considered statistically significant $(\mathrm{S}) ; \geq$ 0.05 was considered statistically insignificant (NS).

\section{Results}

The demographic data of RA patients is shown in (Table 1). Frequency of subclinical MSUS lesions in RA patients and their shoulder joints are presented in Table 2. The total MSUS lesions were present in 75\% of RA patients, articular lesions were present in 52.5\%, and peri-articular were present in 68.8\%, while the total MSUS lesions were present in $65 \%$ of RA shoulders, articular lesions were present in 
Table 1 Demographic data of RA patients

\begin{tabular}{lll}
\hline Items & & $\begin{array}{l}\text { RA patients }(n=80) \\
\text { No. }(\%)\end{array}$ \\
\hline Age (years) & Mean \pm SD & $43.0 \pm 13.1$ \\
& Range & $20-70$ \\
Sex & Female, N (\%) & $58(72.5 \%)$ \\
& Male, N (\%) & $22(27.5 \%)$ \\
Occupation & Not working, N (\%) & $14(17.5 \%)$ \\
Disease duration & Working, N (\%) & $66(82.5 \%)$ \\
& Mean \pm SD & $3.45 \pm 1.6$ \\
Smoking & Range & $1-7$ \\
& No, N (\%) & $(100 \%)$ \\
& Yes, N (\%) & 0 \\
\hline
\end{tabular}

$36.9 \%$, and peri-articular were present in $57.5 \%$ of shoulders (not all 60 patients affected had bilateral shoulder lesions but only 44 (73.3) had bilateral and 16 (26.6) had unilateral affection so the total shoulder joint affections are not double the number of total patients affected). The frequency of subclinical MSUS lesion sub-types in RA shoulder joints is seen in Fig. 1 with the most frequent lesion being supraspinatus tendinopathy $(43.12 \%)$ followed by SASDs bursitis [total (31.87\%), effusion (16.87\%), and synovial hypertrophy (15\%)], and then the supraspinatus tendon partial tear (30.62\%) and long head of biceps tenosynovitis (effusion only not synovial hypertrophy) (28.75\%), while the subscapularis tendinopathy was $14.37 \%$ and subscapularis tendon partial tear was 9.37\%. The articular changes of the shoulder joint were in the following order: acromioclavicular joint synovitis (26.87\%), acromioclavicular joint osteophyte (23.75\%), glenohumeral joint synovitis (12.5\%) [total (12.5\%), effusion $(7.5 \%)$, synovial hypertrophy $(5 \%)]$, and glenohumeral joint erosion (11.25\%) (Figs. 2, 3, and 4).

The association between peri-articular and articular subclinical MSUS shoulder joint lesions in RA patients and their disease characteristics are shown in Tables 3 and 4 . There was a significant association between periarticular subclinical US lesions and both older age and longer disease duration and comorbidity (Table 3). Also, there was a significant association between articular subclinical MSUS lesions and positive RF, DAS-28 score, and disease duration (Table 5).

The significant predictors for both peri-articular and articular subclinical shoulder joint changes by MSUS in RA patients are shown in Table 5 where older age and longer disease duration were significant predictors for periarticular changes, while RF positive, longer disease duration, and higher DAS-28 scores (moderate and severe activity) were significant predictors for articular changes.

\section{Discussion}

MSUS is a widely accepted imaging technique in both clinical practice and in rheumatology research to visualize joints and soft tissues. This procedure has several benefits such as the absence of side effects, speed of realization, sensitivity for detecting erosions, and availability in a routine practice [10]. The objectives of our study were to assess the prevalence and types of subclinical MSUS lesions of both shoulder joints in RA patients and their predictors. We found that more than half of the patients (75\%) have subclinical MSUS changes in their clinically silent (inactive) shoulder joints where $65 \%$ of the patient's shoulders are affected, and this is higher than the recently reported data in a study of healthy subjects done by Iganocci et al. [11] in which the MSUS changes were present in $28.9 \%$ of the normal shoulders. At the same time, we agree with the study done by Naranjo et al. [12] in which they found that the total MSUS changes in 67 painless RA shoulders were $52 \%$.

The most frequent MSUS changes of the shoulder joint in our RA population were in the peri-articular structures and not in the articular one. Our study goes in agreement with many studies done on both painless and painful RA shoulders as regards the higher percentage of the peri-articular changes. We found that supraspinatus tendinopathy was the most frequent MSUS change which was present in $43.12 \%$ of our patient's shoulders and also subscapularis tendinopathy was present in $14.37 \%$. This percentage is higher than the average percent present in the normal population in Iganocci et al.'s study [11], in which the supraspinatus tendinopathy percentage was $20.6 \%$, but we agree in this high percentage with a study done by Fuda et al. [13] on 40 RA patients in which the rotator cuff tendinopathy

Table 2 Frequency of subclinical MSUS lesions in RA patients and their shoulder joints

\begin{tabular}{llll}
\hline Subclinical ultrasound shoulder lesions & RA patients (80) & Subclinical ultrasound shoulder lesions & $\begin{array}{l}\text { RA shoulder joints (160) } \\
\text { No. (\%) }\end{array}$ \\
\hline Total lesions & $60(75.0)$ & Total lesions & $104(65.0)$ \\
Articular lesions & $42(52.5)$ & Articular lesions & $59(36.9)$ \\
Peri-articular lesions & $55(68.8)$ & Peri-articular lesions & $92(57.5)$ \\
Unilateral lesions & $16(26.6)$ & Right shoulder lesions & $54(51.9)$ \\
Bilateral lesions & $44(73.3)$ & Left shoulder lesions & $50(48.0)$ \\
\hline
\end{tabular}




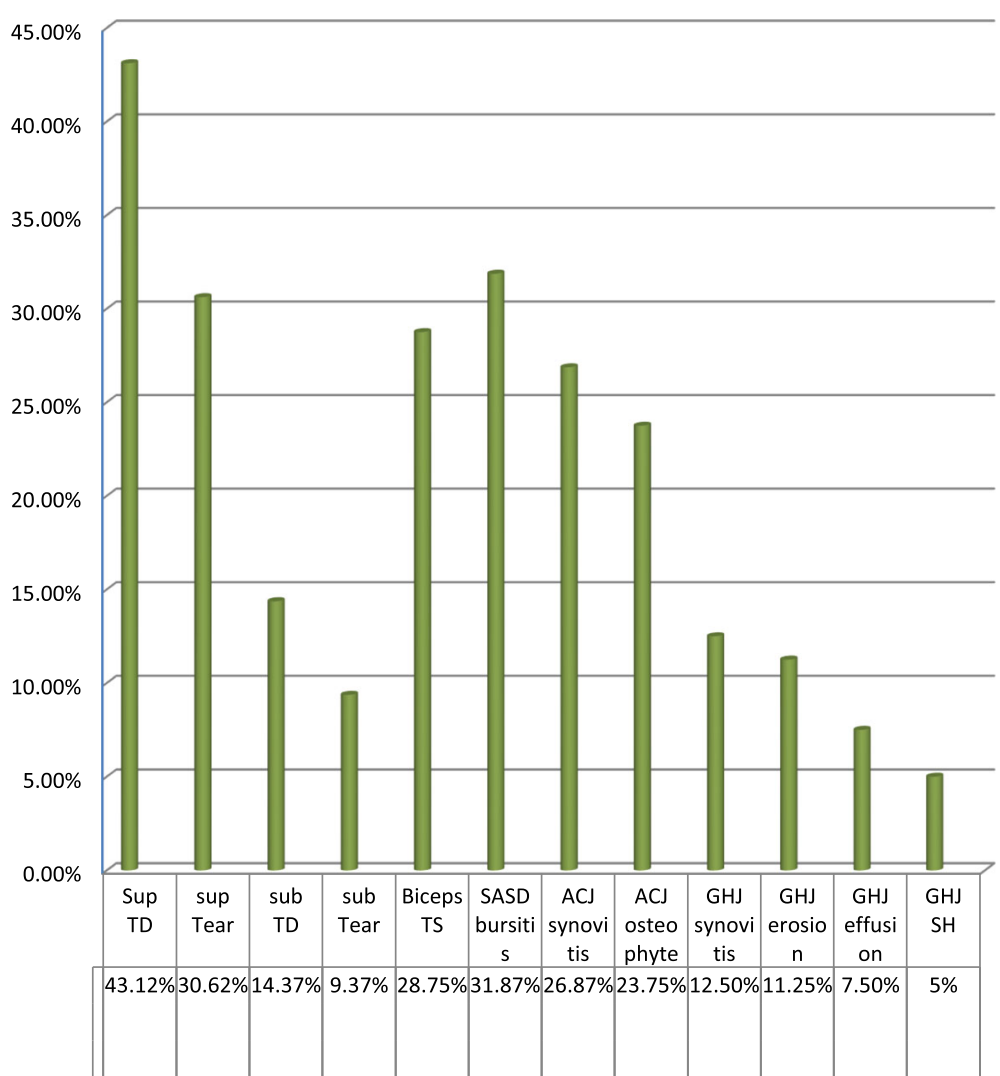

Fig. 1 Bar chart showing the peri-articular and articular subclinical ultrasonography subtype changes in RA shoulder joints. Articular lesions are ACJ synovitis, ACJ osteophyte, GHJ synovitis (GHJ, SH, and GHJ effusion), and GHJ erosion), while peri-articular lesions are Sup TD, Sup tear, Sub TD, Sub tear, biceps TS, and SASD bursitis; Sup TD, supraspinatous tindinopathy; sup, supraspinatous; sub TD, subscapularis tendinopathy; sub, subscapularis; TS, tenosynovitis; SASD, subacromial subdeltoid; ACJ, acromioclavicular joint; GHJ, glenohumeral joint; SH, synovial hypertrophy

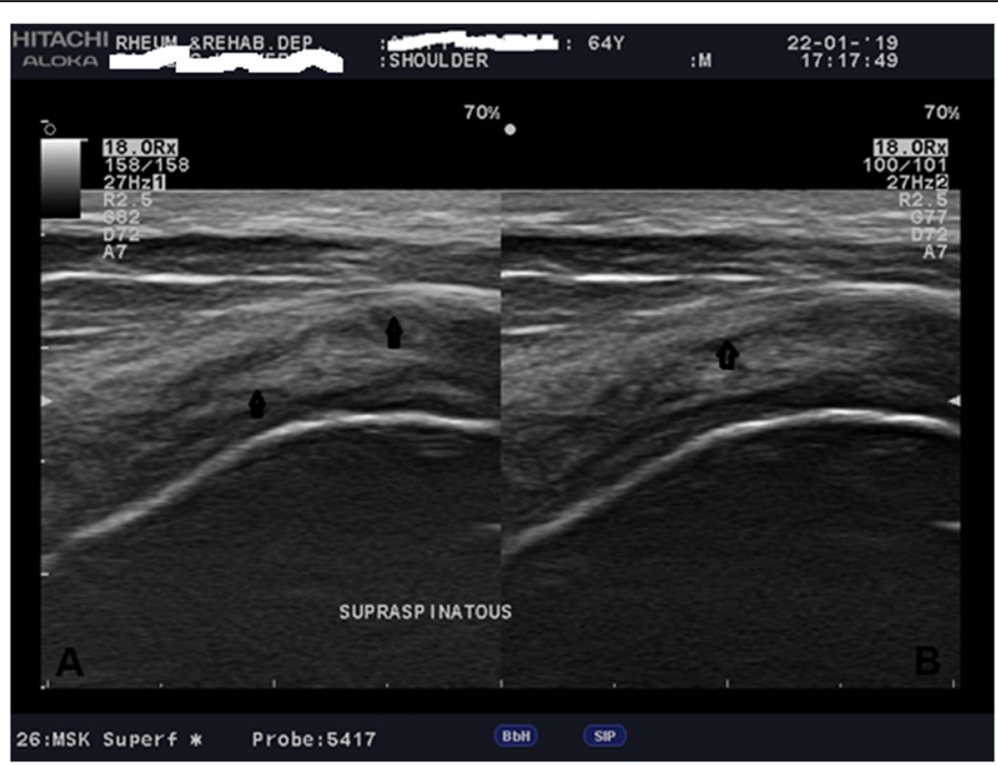

Fig. 2 Left supraspinatus tendinopathy. a Longitudinal view. $\mathbf{b}$ Transverse view of the left supraspinatous tendon of the left shoulder joint. Arrows showed architectural distortion with loss of the normal fibrillar echopattern 


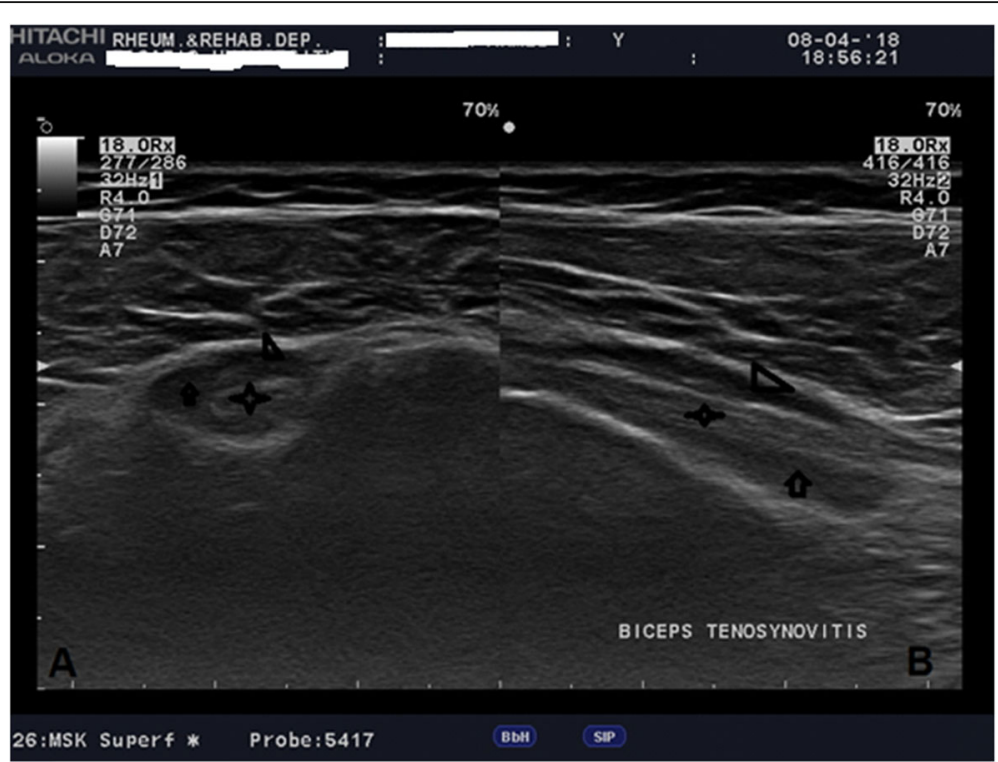

Fig. 3 Right biceptal tenosynovitis. a Longitudinal view. b Transverse view of the right long head of biceps tendon of the right shoulder joint. Asterisks showed the tendon fibers, arrows showed synovial hypertrophy, and arrow heads showed effusion around the tendon inside its synovial sheath

was present in $45 \%$ of the shoulders, although this study was done on active painful shoulders only. As regards the SASD bursitis, we found that $31.78 \%$ of our patient's shoulders showed SASD bursitis with $16.87 \%$ effusion and $15 \%$ synovial hypertrophy, and also this is higher than the percentage of SASD bursitis present in the normal population in Iganocci et al.'s study [11], in which they found that SASD bursitis effusion was present in $11.3 \%$ and synovial hypertrophy was present in $2.1 \%$. But also, we still agree regarding the findings with many studies like the study done by Elbinoune et al. [14] in which they evaluated 37 RA patients with painful and painless shoulder joints and found that SASD bursitis was present in $37.8 \%$ of the patient's shoulders; another study agreed with us which was done by Stegbauer et al. [10] on painful shoulders in 99 RA patients, and they found that SASD bursitis was present in $(35 \%)$ of the shoulders; also another study on painful shoulders in 44

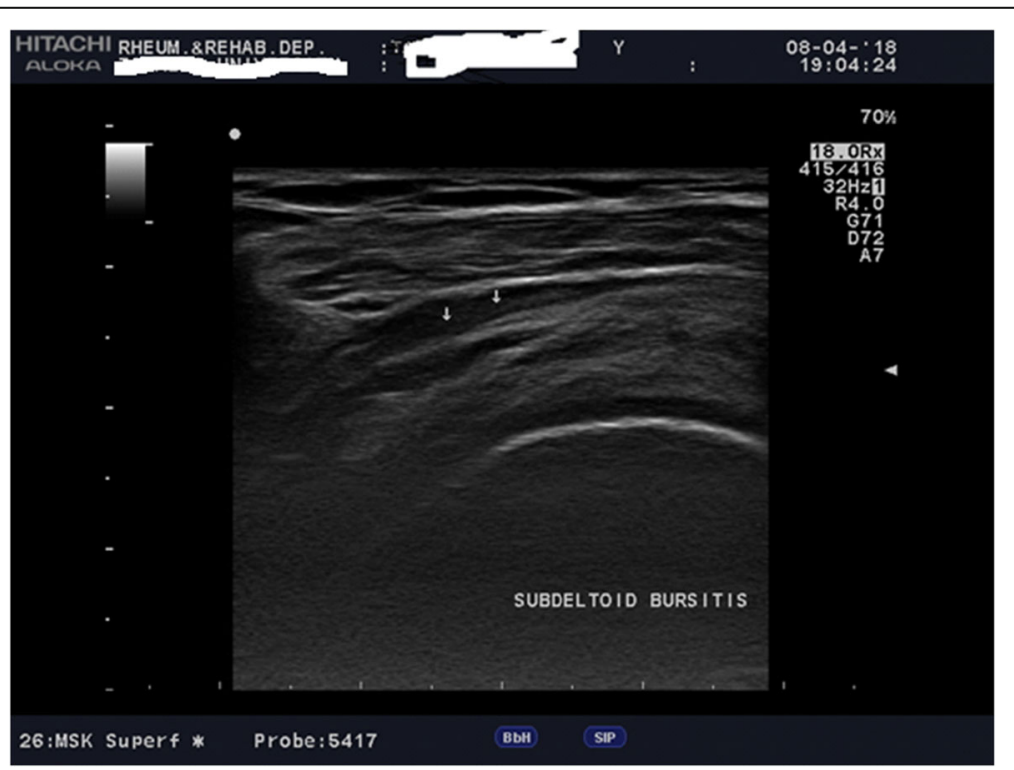

Fig. 4 Left subdeltoid bursitis. Longitudinal view of the left rotator cuff of the left shoulder joint. arrows showed hypoechoic area inside the subdeltoid bursa (synovial hypertrophy) 
Table 3 Association between peri-articular subclinical ultrasound shoulder joint lesions in RA patients and their demographic, clinical and treatment parameters

\begin{tabular}{|c|c|c|c|c|c|}
\hline \multirow[t]{2}{*}{ Rheumatoid patients } & & \multicolumn{3}{|l|}{ RA patients (80) } & \multirow[t]{2}{*}{$p$} \\
\hline & & With periarticular lesions, $N(\%)$ & Without peri-articular lesions, $N(\%)$ & $\overline{x^{2}}$ & \\
\hline \multirow[t]{2}{*}{ Sex } & Female & $41(70.7)$ & $17(29.3)$ & 58 & 0.54 \\
\hline & Male & $14(63.6)$ & $8(36.4)$ & 22 & \\
\hline \multirow[t]{2}{*}{ Occupation } & Non manual worker & 8 & 6 & 14 & 0.3 \\
\hline & Manual worker & 47 & 16 & 66 & \\
\hline \multirow[t]{2}{*}{ Co-morbidity } & Yes & $14(93.3)$ & $1(6.7)$ & 15 & $0.04^{*}$ \\
\hline & No & $41(63.1)$ & $24(36.9)$ & 65 & \\
\hline \multirow[t]{2}{*}{ RF } & + ve & $45(72.5)$ & $17(27.5)$ & 62 & 0.27 \\
\hline & - ve & $10(55.5)$ & $8(44.5)$ & 18 & \\
\hline \multirow[t]{2}{*}{ Anti-CCP } & + ve & $36(70.5)$ & $15(29.5)$ & 51 & 0.82 \\
\hline & - ve & $19(65.5)$ & $10(34.5)$ & 29 & \\
\hline \multirow[t]{2}{*}{ NSAID } & Yes & $28(68.3)$ & $13(31.7)$ & 41 & 0.9 \\
\hline & No & $27(69.2)$ & $12(30.8)$ & 39 & \\
\hline \multirow[t]{2}{*}{ Steroid } & Yes & $51(69)$ & $23(31)$ & 74 & 0.73 \\
\hline & No & $4(66.6)$ & $2(33.4)$ & 6 & \\
\hline Age (years) & Mean \pm SD & $49 \pm 9$ & $29 \pm 8.5$ & $U$ & $0.001^{*}$ \\
\hline ESR & Mean \pm SD & $36 \pm 23$ & $34 \pm 17$ & $U$ & 0.95 \\
\hline Disease duration (years) & Mean \pm SD & $4 \pm 1.5$ & $2.2 \pm 1.2$ & $U$ & $0.001^{*}$ \\
\hline CRP & Mean \pm SD & $7.6 \pm 4.2$ & $7.8 \pm 3.6$ & $U$ & 0.6 \\
\hline \multirow[t]{3}{*}{ DAS-28 } & Mild & $4(40)$ & $6(60)$ & 10 & 0.054 \\
\hline & Moderate & $44(75.8)$ & $14(24.2)$ & 58 & \\
\hline & Severe & $7(58.4)$ & $5(41.6)$ & 12 & \\
\hline
\end{tabular}

ESR erythrocyte sedimentation rate, $C R P$ C-reactive protein, $R F$ rheumatoid factor, anti-CCP anti-cyclic citrullinated peptide antibodies, $D A S$-28 score 28 -joint count disease activity score, NSAID non-steroidal anti-inflammatory drugs, $U$ Mann-Whitney test, $\chi^{2}$ chi-square test

*Added values are significant at $p<0.05$

RA patients done by Mohamed et al. [15] in which they found that SASD bursitis was present in $43.75 \%$ of shoulder joints. The smallest percent of SASD bursitis effusion was present in a study done by Kim et al. [16] on 30 RA patients with 25 non-painful shoulders and 35 painful shoulders and was present in $4 \%$ and $14.3 \%$, respectively, and this discrepancy in SASD bursitis percentage may be due to a large number of patients in our study with higher percentage of comorbidities (63.7\%) mainly diabetes mellitus which may cause peri-articular shoulder changes. As regards the rotator cuff tears, we found in our population a relatively higher percentage of partial thickness tear in supraspinatus tendon (30.7\%), while subscapularis tendon partial thickness tear was 9.6\%. Also, these results were still higher than the normal values in Iganocci's et al.'s [11] study in which the supraspinatus tendon partial tear was $7.9 \%$ in young age and $8.3 \%$ in old age, but also our results are in agreement with Ruta et al.'s [17] study in which the rotator cuff partial tear percentage was 35\% and also Alasaarela and Alasaarela's [18] study in which the supraspinatus tendon changes were present in 33\% of painful shoulders.
On the other hand, our percentage of partial rotator cuff tear was higher than the other studies like Kim et al. [16] which was $20 \%$ in subscapularis tendon and $16 \%$ in supraspinatus tendon in both painful and non-painful shoulders. Also, in Stegbauer et al.'s [10] study, it was 15\% in painful shoulders, and in Sakellariou et al.'s [14 ] study, it was 11\% in both tender and non-tender joints. We can explain our high percent of rotator cuff tears by that our patients had a large number of manual workers (farmers) which may cause traumatic tears and also the high frequency probe (18 $\mathrm{MHz}$ ) of the apparatus we used.

As regards the long head of biceps tenosynovitis, our patients showed $28.75 \%$ effusion in bicepital sheath. Like the previous findings, this was higher than the normal percentage present in Iganocci et al.'s [11] study in which the long head of biceps tenosynovitis (effusion) was $16.5 \%$, and we agreed in this finding with a study that was done by Kim et al. [16] in which the biceps tendon effusion was present in 36\% of non-painful shoulder joints; also in a study done by Stegbauer et al. [10], the biceps tenosynovitis was seen in $35 \%$ of painful shoulders, in Coari et al.'s [19] study, the percentage of biceps 
Table 4 Association between articular subclinical ultrasound shoulder joint lesions in RA patients and their demographic, clinical, and treatment parameters

\begin{tabular}{|c|c|c|c|c|c|}
\hline \multirow[t]{2}{*}{ Rheumatoid patients } & & \multicolumn{3}{|l|}{ RA patients (80) } & \multirow[t]{2}{*}{$p$} \\
\hline & & With articular lesions, No (\%) & Without articular lesions, No (\%) & $\overline{x^{2}}$ & \\
\hline \multirow[t]{2}{*}{ Sex } & Female & $28(48.3)$ & $30(51.7)$ & 58 & 0.22 \\
\hline & Male & $14(63.6)$ & $8(36.4)$ & 22 & \\
\hline \multirow[t]{2}{*}{ Occupation } & Non-manual worker & 8 & 6 & 14 & 0.7 \\
\hline & Manual worker & 34 & 32 & 66 & \\
\hline \multirow[t]{2}{*}{ Co-morbidity } & Yes & $9(60)$ & $6(40)$ & 15 & 0.71 \\
\hline & No & $33(50.7)$ & $32(49.3)$ & 65 & \\
\hline \multirow[t]{2}{*}{ RF } & + ve & $41(66.2)$ & $21(33.8)$ & 62 & $0.0002^{*}$ \\
\hline & - ve & $1(5.5)$ & $17(94.5)$ & 18 & \\
\hline \multirow[t]{2}{*}{ Anticcp } & + ve & $31(60.7)$ & $20(39.3)$ & 51 & 0.08 \\
\hline & - ve & $11(38)$ & $18(62)$ & 29 & \\
\hline \multirow[t]{2}{*}{ NSAID } & Yes & $20(49)$ & $21(51)$ & 41 & 0.5 \\
\hline & No & $22(56.4)$ & $17(43.6)$ & 39 & \\
\hline \multirow[t]{2}{*}{ Steroid } & Yes & $39(52.7)$ & $35(47.3)$ & 74 & 0.76 \\
\hline & No & $3(50)$ & $3(50)$ & 6 & \\
\hline Age (years) & Mean \pm SD & 42. \pm 10 & $43.8 \pm 16$ & $U$ & 0.6 \\
\hline ESR & Mean \pm SD & $38 \pm 26$ & $33 \pm 16$ & $U$ & 0.6 \\
\hline Disease duration (years) & Mean \pm SD & $4 \pm 1.5$ & $2.8 \pm 1.6$ & $U$ & $0.001^{*}$ \\
\hline CRP & Mean \pm SD & $8.3 \pm 4.5$ & $7 \pm 3.4$ & $U$ & 0.25 \\
\hline \multirow[t]{3}{*}{ DAS-28 } & Mild & $1(10)$ & $9(90)$ & 10 & $0.0006^{*}$ \\
\hline & Moderate & $30(51.7)$ & $28(48.3)$ & 58 & \\
\hline & Severe & 11 (91.6) & $1(8.4)$ & 12 & \\
\hline
\end{tabular}

ESR erythrocyte sedimentation rate, $C R P$ C-reactive protein, $R F$ rheumatoid factor, anti-CCP anti-cyclic citrullinated peptide antibodies, $D A S$-28 score 28 -joint count disease activity score, NSAID non-steroidal anti-inflammatory drugs, $U$ Mann-Whitney test; $X^{2}$ chi-square test

${ }^{*}$ Added values are significant at $p<0.05$

effusion was $32.2 \%$, and in Ruta et al. [17], it was $23.3 \%$ of painful shoulders, while it was lower than our result in Naranjo et al.'s [12] study in which it was 9\% in painless shoulders. Other studies showed a higher percentage of biceps tenosynovitis in their population as in the study done by Sanja and Mirjana [20] in which it was 81.8\% and in Fuda et al. [13] which was 52.5\%; and in the study of Alasaarela and Alasaarela [18], the percentage was $57 \%$, and this higher percent may be due to that their findings were done on painful shoulders.

Table 5 Logistic regression for predicting variables for both articular and peri-articular subclinical US shoulder joint changes in RA patients

\begin{tabular}{|c|c|c|c|c|}
\hline Variables & $\mathrm{P}($ sig $)$ & Lower limit of $95 \% \mathrm{Cl}$ & Odds ratio & Upper limit of $95 \% \mathrm{Cl}$ \\
\hline \multicolumn{5}{|l|}{ Articular } \\
\hline RF positive & $0.006^{*}$ & 3.6 & 84.58 & 1994 \\
\hline Duration & $0.018^{*}$ & 1.1 & 1.9 & 3.1 \\
\hline \multirow[t]{2}{*}{$\begin{array}{l}\text { DAS28 mild } \\
\text { DAS28 moderate } \\
\text { DAS28 severe }\end{array}$} & $0.038^{*}$ & 1.16 & 14.5 & 181 \\
\hline & $0.000^{*}$ & 9.8 & 144 & 2113 \\
\hline \multicolumn{5}{|l|}{ Peri-Articular } \\
\hline Duration (years) & $0.004^{*}$ & 1.4 & 4 & 10 \\
\hline Comorbidity & 0.07 & 0.85 & 7.8 & 72 \\
\hline Age & $0.0001^{*}$ & 1.1 & 1.3 & 1.5 \\
\hline
\end{tabular}

Cl confidence interval subclinical shoulder affection, $R F$ rheumatoid factor, $D A S 28$ 28-joint count disease activity score

*Added values are significant at $p<0.05$ 
In general, we have a lower percentage of articular MSUS changes in our study, and this may be due to that we study subclinical shoulders and not clinically active joints and our population has relatively smaller disease duration in comparison to other studies.

We found that synovitis in acromioclavicular joint was $26.87 \%$, while the glenohumeral joint synovitis was $12.5 \%$ [ $7.5 \%$ effusion and $5 \%$ synovial hypertrophy]; also we found that the percentage of degenerative osteophytes in acromioclavicular joint was $23.75 \%$, while the percentage of erosion in glenohumeral joint was $12.5 \%$. These findings are still slightly higher than the normal percent present in healthy subjects in the study done by Iganocci et al. [11], in which the acromioclavicular joint effusion was $25.7 \%$ and the acromioclavicular joint osteophyte was $23.7 \%$, while glenohumeral joint effusion was $2.6 \%$, (glenohumeral joint and acromioclavicular joint) synovial hypertrophy was zero, and glenohumeral joint erosion was also zero. These findings are in agreement with the studies done on both painless and painful shoulders like Naranjo et al.'s [12] study, in which the glenohumeral joint effusion was $12 \%$ and glenohumeral joint erosion was $16 \%$ in painless joints; also Kim et al.'s [16] study found glenohumeral joint erosion in $8 \%$ and glenohumeral joint effusion in $20 \%$ of painless shoulders, while Sakellariou et al.'s [21] study found that glenohumeral joint involvement was present in $14 \%$, humeral head erosion in $25 \%$, and acromioclavicular joint synovitis in $26.87 \%$ of both painful and painless shoulders, while studies done on painful shoulders only showed higher percentage than ours; like in Fuda et al.'s [13] study, they found glenohumeral joint synovitis in $45 \%$ and glenohumeral joint erosion in 52.5\%, and in Mohammed et al.'s [15] study, the glenohumeral joint synovitis was present in 93.7\% and erosions in $29.2 \%$ of the patient's shoulders. When we studied the association between subclinical MSUS changes and the patient's characteristics, we found that the peri-articular changes were statistically significantly associated with older age, increased comorbidities present in RA patients, and longer disease durations, but comorbidities are not significant as a predictor for these changes, while the factors associated with and predicted for articular changes were high disease activity, long disease duration, and seropositive RF. We agree in these findings with the following studies done on the clinically affected shoulders in RA patients. In a study on shoulder joints in 37 RA patients by Elbinoune et al. [14], they found that the MSUS changes in shoulder joints were associated with advanced age and found that MSUS inflammatory findings in anterior recess of glenohumeral joint were linked to a higher level of rheumatoid factor and the SASDs bursitis was not associated nor with a high disease activity, nor with elevated ESR or CRP. Also, a study by Sakellariou et al. [21] found that patients with MSUS inflammatory involvement had longer median disease duration, RF positive, higher disease activity, and higher acute phase reactants. A study also done by Fuda et al. [13] found a significant relation between MSUS-detected erosion in RA patients and disease duration and RF level as the erosion is a destructive process, and this may explain the cause of a small number of erosion in our study as our patients have relatively small disease duration.

\section{Conclusion}

Although clinically silent shoulders in RA patients, we found a high percentage of subclinical abnormalities detected by MSUS examination. These changes were more predominant in the peri-articular structure of the shoulder joints than in the articular structure with confirmation of the finding of power Doppler as an indicator of active joint inflammation as we did not find any power Doppler activity in our population. Older age and longer disease duration were significant predictors for the periarticular changes while high disease activity, seropositive $\mathrm{RF}$, and longer disease duration were significant predictors for the articular changes. So clinical examination of RA shoulders is not conclusive in all patients and MSUS is a simple and non-invasive technique which can be used to detect subclinical affection in those patients. From the results of our present study, we can recommend to do routine regular ultrasonography examination of both shoulder joints in all patients with RA even if asymptomatic as this will help in early detection of the changes, to alarm the patients with RA about the importance of early treatment to prevent further complications and to achieve remission.

The limitation of our study is the small number and absence of a comparison control group so further studies on larger cohort of RA patients with longer disease duration and variable risk factors compared to apparently healthy people to show more structure damaging subclinical ultrasonography changes in both shoulder joints and to show the effect of subclinical shoulder lesions on functional impairment and quality of life in RA patients. It should be noted that articular changes could be a predisposing factor for the development of periarticular changes as they definitely cause disordered biomechanics of the shoulder joint complex.

\section{Abbreviations}

RA: Rheumatoid arthritis; MSUS: Musculoskeletal ultrasonography; ACR/ EULAR: American College of Rheumatology/European League Against Rheumatism; ESR: Erythrocyte sedimentation rate; CRP: C-reactive protein; RF: Rheumatoid factor; anti-CCP: Anti-cyclic citrullinated peptide antibodies; DAS-28 score: 28-joint count disease activity score; EULAR: European League Against Rheumatism; SASD: Subacromial subdeltoid; OMERACT: Outcome measures in rheumatology clinical trials

Acknowledgements

No specific acknowledgements. 


\section{Authors' contributions}

SA contributed to the conception and design of the work, interpretation of the data, and revision of the work; had approved the submitted version (and any substantially modified version); and, finally, had agreed both to be personally accountable for her own contributions and to ensure that questions related to the accuracy or integrity of any part of the work, even ones in which she was not personally involved, are appropriately investigated, resolved, and the resolution documented in the literature. EE contributed to the conception and had revised it, AE contributed to the design of the work; the acquisition, analysis, and interpretation of data; and writing the work. MH contributed to the conception, design of the work, and the acquisition, analysis, interpretation of the data; revised it, and also had approved the submitted version. N.B: All authors have read and approved the final manuscript.

\section{Funding}

No funding for this article.

\section{Availability of data and materials}

Not applicable

\section{Ethics approval and consent to participate}

Written informed consent was obtained from patients for their study participation. The study was approved by the local ethical committee of Zagazig University Hospitals by the number (3930/13-8-2017).

\section{Consent for publication}

Written informed consent was obtained from patients for publication of this work.

\section{Competing interests}

No conflict of interest.

\section{Author details}

'Rheumatology and Rehabilitation Department, Faculty of Medicine, Zagazig University, Zagazig, Egypt. ${ }^{2}$ Rheumatology and Rehabilitation Department, Belqas Hospital, Belqas, Egypt.

Received: 27 March 2020 Accepted: 5 May 2020

Published online: 09 June 2020

\section{References}

1. Choy E (2012) Understanding the dynamics: pathways involved in the pathogenesis of rheumatoid arthritis. Rheumatology (Oxford) 51(Suppl 5): v3-v11

2. Kanasawa T, Nishino J, Tohma S (2013) Analysis of the affected joints in rheumatoid arthritis patients in alarge Japanese cohort. Mod Rheumatol 23: 44-49

3. Smolen JS, Aletaha D, Bijlsma JW, Breedveld FC, Boumpas D, Burmester G et al (2010) Treating rheumatoid arthritis to target: recommendations of an international task force. Ann Rheum Dis 69(4):631-637

4. Aletaha D, Neogi T, Silman AJ, Funovits J, Felson T, Bingham CO et al (2010) Rheumatoid arthritis classification criteria: an American College of Rheumatology/European League Against Rheumatism collaborative initiative. Arthritis Rheum 62(9):2569-2581

5. Westergren A (1957) Diagnostic tests: the erythrocyte sedimentation rate range and limitations of the technique. Inn Med Kinderheilkunde 3:20-25

6. Van Gaalen FA, Visser H, Huizinga TW (2005) A comparison of the diagnostic accuracy and prognostic value of the first and second anti-cyclic citrullinated peptides (CCP1 and CCP2) autoantibody tests for rheumatoid arthritis. Ann Rheum Dis 64:1510-1512

7. Prevoo ML, Hof Van't MA, Kuper HH, van MA L, van de LBA P, van PLCM R (1995) Modified disease activity scores that include twenty-eight-joint counts. Development and validation in a prospective longitudinal study of patients with rheumatoid arthritis. Arthritis Rheum 38(1):44-48

8. Ingrid M, Janta I, Backhaus M, Ohrndorf S, Bong DA, Martinoli C et al (2017) The 2017 EULAR standardised procedures for ultrasound imaging in rheumatology. Ann Rheum Dis 0:1-6

9. Richard J., Wakefield PV et al (2005) Musculoskeletal ultrasound including definitions for ultrasonographic pathology. J Rheumatol 32:2485-2487
10. Johannes S, Christian L, Stefan M (2008) Sites of infammation in painful rheumatoid shoulder assessed by musculoskeletal ultrasound and power Doppler sonography. Rheumatol Int 28:459-465

11. lagnocco A, Filippucci E, Sakellariou G, Ceccarelli F, Geso D, Carli L et al (2013) Ultrasound imaging for the rheumatologist XLIV. Ultrasound of the shoulder in healthy individuals. Clin Exp Rheumatol 31:165-171

12. Naranjo A, Marrero-Pulido T, Ojeda S, Francisco F, Erausquin C, Rua-Figueroa I et al (2002) Abnormal sonographic findings in the non-painful arthritic shoulder. Scand J Rheumatol 31:17-21

13. Fudaa Al, Ismail N, Galalb O (2015) Ultrasonographic findings of the shoulders in Egyptian patients with rheumatoid arthritis. Egyptian Rheumatology \& Rehabilitation 44:17-23

14. Elbinoune I, Amine B, Moudjibou W, Rkain H, Aktaou S, Hajjaj-Hassouni N (2016) Rheumatoid shoulder assessed by ultrasonography: prevalence of abnormalities and associated factors. Pan African Medical Journal 24:235

15. Mohamed Moneer Rayan, Ahmed Mosallam Ebrahim, Ahmed Aly Abdelaziz and Saad Rizk Abdelwahed. Assesment of site of inflammation in painful Rheumatoid shoulder by muskeloskeletal ultrasonography, power Doppler sonography and magnetic resonance imaging. AAMJ. 2012;10 N.2.

16. Kim HA, Kim SH, Seo Y (2007) Ultrasonographic findings of the shoulder in patients with rheumatoid arthritis and comparison with physical examination. J Koran Med Sci 22:660-666

17. Ruta S, Rosa J, Navarta D A, Saucedo C, Catoggio L and Soriano E. Ultrasound assessment of new onset bilateral painful shoulder in patients with polymyalgia rheumatica and rheumatoid arthritis 2012.

18. Alasaarela EM and Alasaarela EL Ultrasound evaluation of painful rheumatoid shoulders J Rheumatol. Sep 1994;21(9):1642-1648

19. Coari G, Paoletti F, lagnocco A (1999) Shoulder involvement in rheumatic diseases. Sonographic findings J Rheumatol 26:668-673

20. Sanja MR, Mirjana ZS (2010) Ultrasonographic study of the painful shoulder in patients with rheumatoid arthritis and patients with degenerative shoulder disease. Acta Rheumatol Port 35(1):50-58

21. Sakellariou G, lagnocco A, Filippucci E (2013) Ultrasound imaging for the rheumatologist. Ultrasound of the shoulders of patients with rheumatoid arthritis Clin Exp Rheumatol 31:837-842

\section{Publisher's Note}

Springer Nature remains neutral with regard to jurisdictional claims in published maps and institutional affiliations.

\section{Submit your manuscript to a SpringerOpen ${ }^{\circ}$ journal and benefit from:}

- Convenient online submission

- Rigorous peer review

- Open access: articles freely available online

- High visibility within the field

- Retaining the copyright to your article

Submit your next manuscript at $>$ springeropen.com 